\title{
Report on FY16 Low-dose Metal Fuel Irradiation and PIE
}

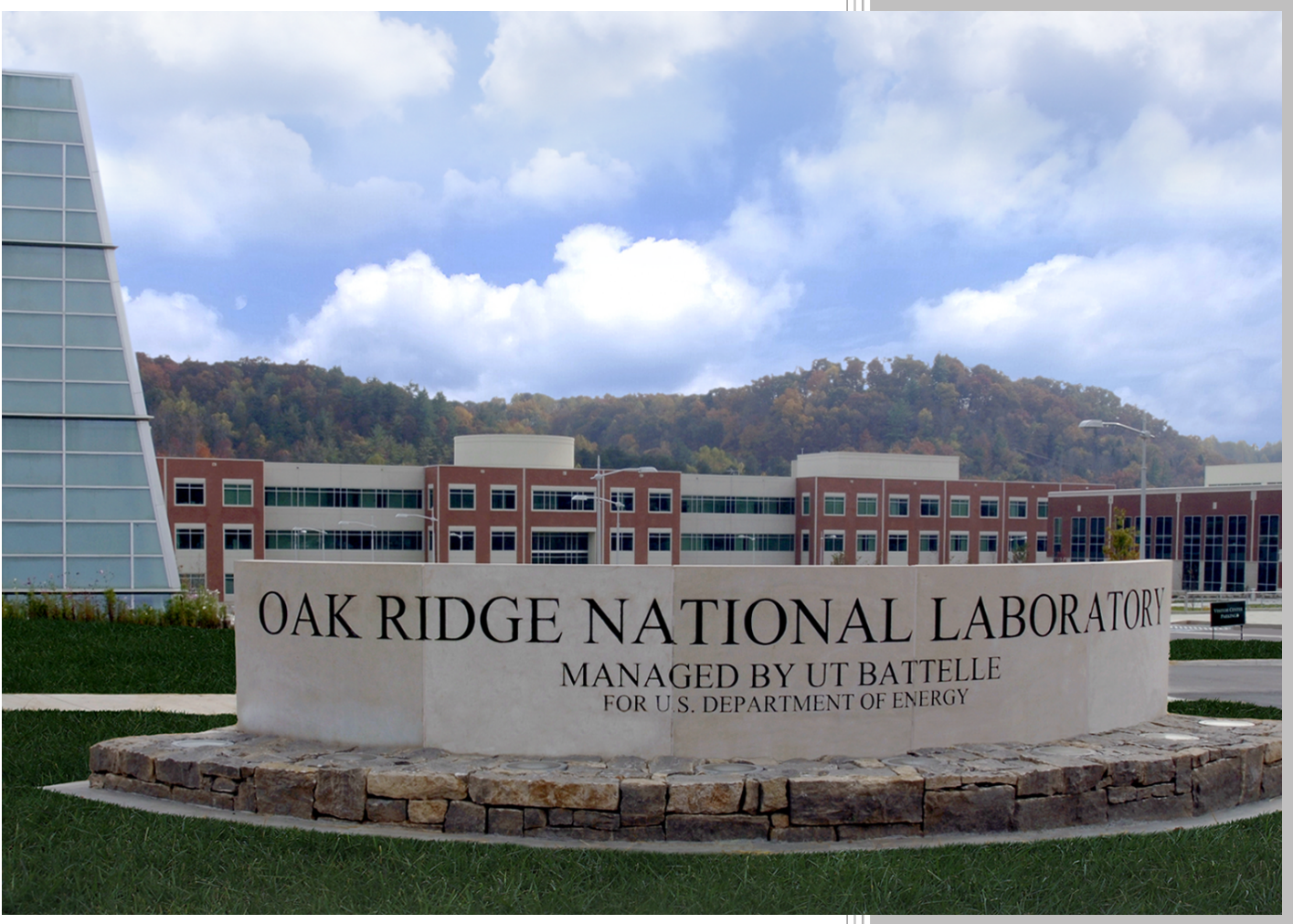

Approved for public release.

Distribution is unlimited.

Philip D Edmondson

September 15, 2016 


\title{
DOCUMENT AVAILABILITY
}

Reports produced after January 1, 1996, are generally available free via US Department of Energy (DOE) SciTech Connect.

Website: http://www.osti.gov/scitech/

Reports produced before January 1, 1996, may be purchased by members of the public from the following source:

\author{
National Technical Information Service \\ 5285 Port Royal Road \\ Springfield, VA 22161 \\ Telephone: 703-605-6000 (1-800-553-6847) \\ TDD: $703-487-4639$ \\ Fax: 703-605-6900 \\ E-mail: info@ntis.fedworld.gov \\ Website: http://www.ntis.gov/help/ordermethods.aspx
}

Reports are available to DOE employees, DOE contractors, Energy Technology Data Exchange representatives, and International Nuclear Information System representatives from the following source:

Office of Scientific and Technical Information

PO Box 62

Oak Ridge, TN 37831

Telephone: $865-576-8401$

Fax: 865-576-5728

E-mail: report@osti.gov

Website: http://www.osti.gov/contact.html

This report was prepared as an account of work sponsored by an agency of the United States Government. Neither the United States Government nor any agency thereof, nor any of their employees, makes any warranty, express or implied, or assumes any legal liability or responsibility for the accuracy, completeness, or usefulness of any information, apparatus, product, or process disclosed, or represents that its use would not infringe privately owned rights. Reference herein to any specific commercial product, process, or service by trade name, trademark, manufacturer, or otherwise, does not necessarily constitute or imply its endorsement, recommendation, or favoring by the United States Government or any agency thereof. The views and opinions of authors expressed herein do not necessarily state or reflect those of the United States Government or any agency thereof. 
Materials Science \& Technology Division

\title{
REPORT ON FY16 LOW-DOSE METAL FUEL IRRADIATION AND PIE
}

\author{
Philip D Edmondson
}

Date Published: September 15, 2016

\section{Work Package Title: Irradiation Testing in HFIR Work Package \#: FT-16OR02030303 \\ Work Package Manager: Philip D Edmondson \\ Milestone \#: M3FT-16OR020303031}

Prepared under the direction of the

U.S. Department of Energy

Office of Nuclear Energy

Fuel Cycle Research and Development

Advanced LWR Fuels

\author{
Prepared by \\ OAK RIDGE NATIONAL LABORATORY \\ P.O. Box 2008 \\ Oak Ridge, Tennessee 37831-6285 \\ managed by \\ UT-Battelle, LLC \\ for the \\ US DEPARTMENT OF ENERGY \\ under contract DE-AC05-00OR22725
}





\section{CONTENTS}

Page

LIST OF FIGURES $\ldots \ldots \ldots \ldots \ldots \ldots \ldots \ldots \ldots \ldots \ldots$

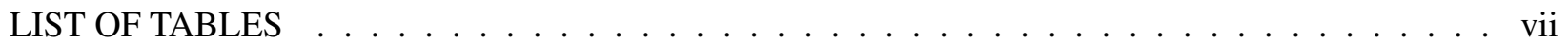

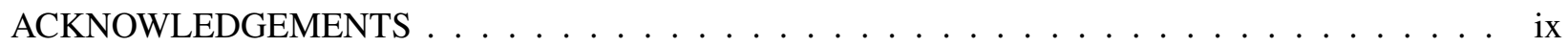

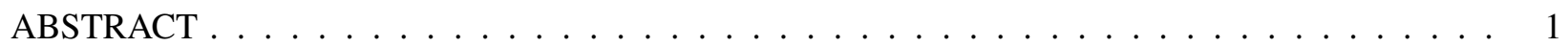

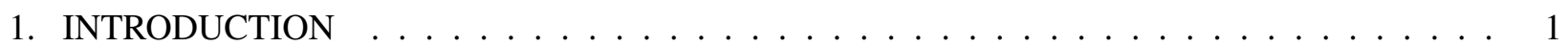

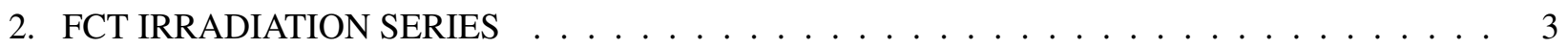

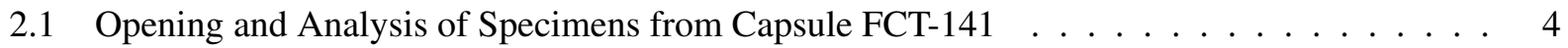

2.1 .1 Opening FCT-141 at IMET . . . . . . . . . . . . . . . . . 4

2.1.2 Initial Characterization of FCT-141 Specimens and Temperature Monitors . . . . . . 4

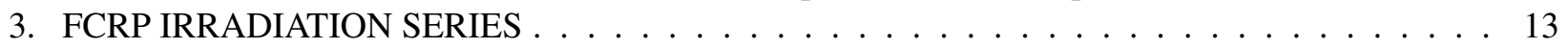

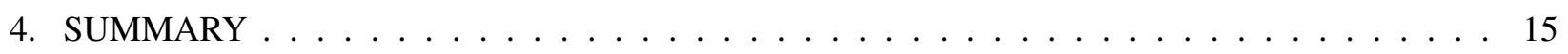





\section{LIST OF FIGURES}

Figures

Page

1 FCT series, TEM rabbit capsule design features the use of Gd spacers (22.86 mm stack length) that also serve as the thermal neutron shield. Space is provided for a maximum of 6 TEM disks samples. SiC temperature monitors and flux monitors displaced some of the TEM disks for the first round of experiments. . . . . . . . . . . . . . . . .

2 SEM micrographs from the center of one side of the disk-shaped sample CP. a)-c) are secondary electron images; d)-f) are back-scatter electron images. The scale bars (white) are:

a) \& d) $500 \mathrm{~nm}$, b) \& e) $400 \mathrm{~nm}$. c) \& f) $100 \mathrm{~nm} . \ldots \ldots \ldots \ldots$

3 SEM micrographs from the edge of of one side of the disk-shaped sample CP. a) -c) are secondary electron images; d)-f) are back-scatter electron images. The scale bars (white) are: a) \& d) $500 \mathrm{~nm}$, b) \& e) $400 \mathrm{~nm}$. c) \& f) $100 \mathrm{~nm}$. . . . . . . . . . . . . . . . . . . .

4 SEM micrographs from the center of one side of the disk-shaped sample CZ. a)-c) are secondary electron images; d) $-\mathrm{f}$ ) are back-scatter electron images. The scale bars (white) are: a) \& d) $500 \mathrm{~nm}$, b) \& e) $400 \mathrm{~nm}$. c) \& f) $100 \mathrm{~nm}$. . . . . . . . . . . . . . . . . . .

5 SEM micrographs from the edge of of one side of the disk-shaped sample CP. a) $-c)$ are secondary electron images; d)-f) are back-scatter electron images. The scale bars (white) are: a) \& d) $500 \mathrm{~nm}$, b) \& e) $400 \mathrm{~nm}$. c) \& f) $100 \mathrm{~nm} \ldots \ldots \ldots$

6 EDS maps recorded from the center of the sample CP. Each map is $2 \mu \mathrm{m}$ across. . . . . . . . 9

7 EDS maps recorded from the edge of the sample CP. Each map is $2 \mu \mathrm{m}$ across. . . . . . . . 9

8 Photographs of the SiC temperatures monitors recovered from FCT-141: a) TM-280, b) TM-294, c) disk TM (no identification). The scale between the green lines is $5 \mathrm{~mm}$. . . . . 10

9 Thermal analysis results from the temperature monitors recovered from the FCT-141 irradiation capsule. The results indicate a maximum irradiation temperature of $\sim 800{ }^{\circ} \mathrm{C}$. . . . . 11

10 FCRP parallelepiped-specimen rabbit capsule design using an outer Gd thermal neutron shield and a removable inner titanium specimen capsule. . . . . . . . . . . . . . 13 



\section{LIST OF TABLES}

Tables Page

1 Summary of the irradiation conditions for the FCT series of irradiations for disk-shaped metallic fuel specimens. . . . . . . . . . . . . . . . . . . . 3

2 Summary of the irradiation conditions for the FCRP series of irradiations for parallelepipedshaped metallic fuel specimens. . . . . . . . . . . . . . . . . . . 13 



\section{ACKNOWLEDGMENTS}

The authors are grateful to Kurt Terrani and Kory Linton of Oak Ridge National Laboratory (ORNL) for their helpful discussion, and the staff at ORNL's High Flux Isotope Reactor (HFIR), and Irradiated Materials Examination and Testing (IMET) Facility for their technical support.

This research was funded by the U.S. Department of Energy's Office of Nuclear Energy, Advanced Fuels Campaign of the Fuel Cycle R\&D program. 



\begin{abstract}
This report gives an overview of the efforts into the low-dose metal fuel irradiation and PIE as part of the Fuel Cycle Research \& Development (FCRD) Advanced Fuels Campaign (AFC) milestone M3FT-16OR020303031. The current status of the FCT and FCRP irradiation campaigns are given including a description of the materials that have been irradiated, analysis of the passive temperature monitors, and the initial PIE efforts of the fuel samples.
\end{abstract}

\title{
1. INTRODUCTION
}

The overarching objectives of this work are to perform irradiation testing of advanced fuels and materials using the High Flux Isotope Reactor (HFIR) Hydraulic Tube Facility (HT) on samples of both disk-shaped (TEM-style) and parallelepiped geometries. The ultimate goal of this effort is to obtain a fundamental understanding of the evolution of the microstructure of metal fuel materials as a function of elemental composition, temperature, and neutron fluence to better understand the in-service behavior and performance of the fuel. To achieve this, low fluence neutron irradiation experiments have been planned and are being performed to provide specimens for detailed post-irradiation examination to generate data to support predictive fuel modeling and simulation code development. Due to the specific requirements of these experiments, this work also established new capabilities within the HFIR HT facility.

The use of irradiation capsules, referred to as "rabbits", inserted into and ejected from the HFIR core during full power ( $85 \mathrm{MW}$ ) operation provides for control of the neutron fluence and temperatures, important parameters in the evolution of the microstructure. The design of the rabbit capsule ensures that the sample is exposed to temperature and neutron spectrum conditions in accordance with irradiation test specifications. The series of tests with uranium metal fuel and iron-based alloy samples will be irradiated under prototypic fast reactor conditions, utilizing a strong thermal neutron absorber to shield the samples from the thermal neutrons while maintaining the fast neutron flux that produces displacement damage similar to fast reactor type conditions.

This summary report gives an up-to-date overview of the status of ORNL's continued support in the AFC's irradiation examinations of advanced metallic fuels. This workpackage includes the design, build, loading, and irradiation in HFIR of Gd-shielded irradiation capsules containing metallic fuel specimens in disk-shaped and parallelepiped geometries. Additionally, the analysis of the $\mathrm{SiC}$ passive temperature monitors is also undertaken at ORNL. 



\section{FCT IRRADIATION SERIES}

The FCT series of irradiations were performed on capsules designed and constructed in FY-14. These capsules used Gd-spacers that acted as thermal neutron shields to contain the metallic fuel specimens. A schematic diagram of the FCT rabbit capsule is shown in Figure 1. The capsules were then irradiated and stored in the HFIR cooling pond until recently. The capsules have recently been packaged ready for shipment to INL for further PIE to be conducted. The specimens materials, irradiation dose (in dpa) and current status is summarized in Table 1.

For capsule FCT-141 - the lowest dose capsule - some initial PIE was conducted that consisted of opening the capsule and basic characterization at ORNL. This opening and base characterization is described below.

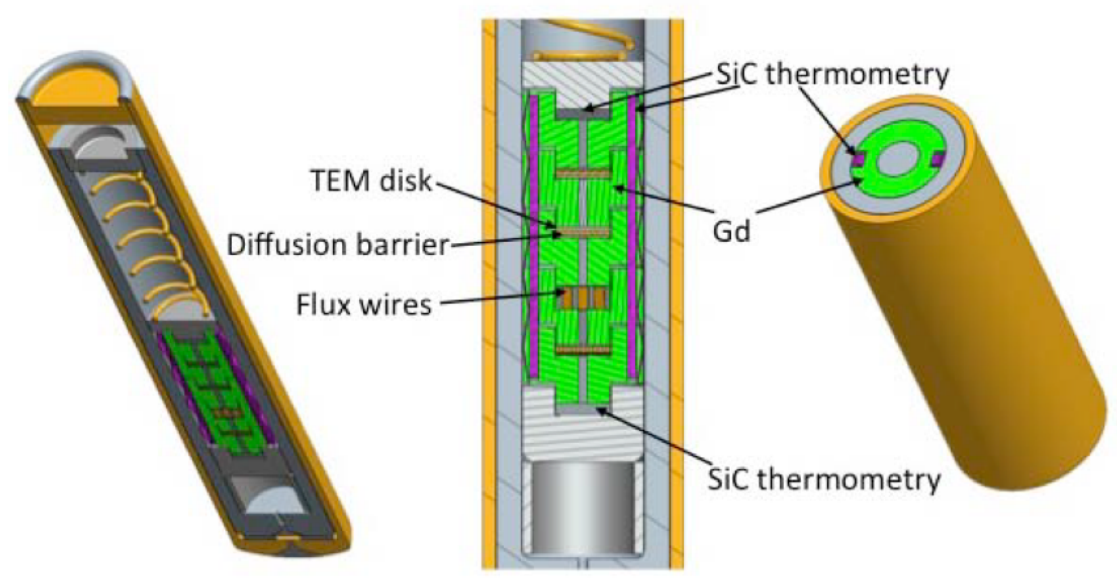

Fig. 1. FCT series, TEM rabbit capsule design features the use of Gd spacers $(22.86 \mathrm{~mm}$ stack length) that also serve as the thermal neutron shield. Space is provided for a maximum of 6 TEM disks samples. SiC temperature monitors and flux monitors displaced some of the TEM disks for the first round of experiments.

Table 1. Summary of the irradiation conditions for the FCT series of irradiations for disk-shaped metallic fuel specimens.

\begin{tabular}{llccl}
\hline Capsule & Fuel & Dose (dpa) & Irradiation Cycle & Status \\
\hline \hline FCT-04 & 3 DU-8.3Zr & 0.3 & 454 & Packaged for shipment to INL \\
FCT-141 & 2 DU & 0.003 & 454 & Opened at ORNL. Waiting shipment to INL \\
FCT-142 & 2 DU & 0.03 & 454 & Packaged for shipment to INL \\
FCT-143 & 1 DU, 2 DU-8.3Zr & 0.56 & 454 & Packaged for shipment to INL \\
FCT-144 & 1 DU, 2 DU-8.3Zr & 1.1 & $454 \& 455$ & Packaged for shipment to INL \\
\hline
\end{tabular}




\subsection{OPENING AND ANALYSIS OF SPECIMENS FROM CAPSULE FCT-141}

\subsubsection{Opening FCT-141 at IMET}

Capsule FCT-141 was exposed to neutrons in HFIR for a total of 3.2 hours. Due to the low activation expected, it was determined that this capsule would be opened at ORNL using the facilities available at IMET. This was successfully undertaken and completed in June 2016. From this capsule, the two disk-shaped metallic fuel specimens - specimen identifiers $\mathrm{CP}$ and $\mathrm{CZ}$ - were recovered, as were two parallelepiped $\mathrm{SiC}$ temperature monitors, and one disk-shaped $\mathrm{SiC}$ temperature monitor.

After opening at IMET, the metallic fuel specimens and temperature monitors were transfered to ORNL's LAMDA facility for initial characterization experiments.

\subsubsection{Initial Characterization of FCT-141 Specimens and Temperature Monitors}

After receipt of the samples in LAMDA from the IMET facility, the specimens were prepared for analysis. The fuel specimens were individually mounted in preparedness for scanning electron microscopy (SEM) and energy dispersive spectroscopy (EDS) characterization as described in §2.1.2.1; the temperature monitor specimens were sent for dilatometry analysis (\$2.1.2.2). The other disk-shaped SiC temperature monitors were observed in the Gd-shielding but could not be recovered despite extensive attempts both in the IMET hot cell facility, and in LAMDA.

\subsubsection{Characterization of Specimens $\mathrm{CP}$ and $\mathrm{CZ}$}

The metallic fuel specimens CP and CZ, recovered from capsules FCT-141, were mounted on an Al stub using carbon sticky-tape. SEM and EDS anlaysis were conducted using LAMDA's FEI Versa 3D dual-beam focussed ion beam (FIB) system, equipped with a Schottky field emitter for high resolution imaging, and an Oxford Instrument XMax ${ }^{N}-150$ EDS collimated detector for EDS measurements.

Secondary electron (SE) and backscatter electron (BSE) images from specimens CP and CZ are shown in Figures 2-5. The images shown in Figures 2 and 3 show representative images from the center and edge of specimen CP, respectively. Similarly, the images shown in Figures 4 and 5 show representative images from the center and edge of specimen $\mathrm{CZ}$, respectively.

As can clearly be seen in the images, there are circular features visible on the surface of sample CP (see, for example, Figure 2); similar features are also observed on sample CZ, but were not as pronounced (Figure 4).

To investigate if the observed circular features were microstructural or chemical, EDS maps of the areas were performed. An EDS map from the center of sample CP is shown in Figure 6; an EDS map from the edge of sample CP is shown in Figure 7.

In both cases (Figures 6 and 7), it is clear that the maps are not directly recorded from the metallic fuel itself. During the capsule design and build, $\mathrm{ZrO}_{2}$ diffusion spacers - as shown in Figure 1 - are used to prevent contamination of the fuel by the gadolinium shielding. The predominant $X$-rays signals generated and recorded by the EDS detector contain both $\mathrm{Zr}$ and Gd (Figures 6 and 7). As such, it appears that the diffusion barriers are still in contact with the metallic fuel specimens. Both sides of sample CP were investigated and showed $\mathrm{Zr}$ and $\mathrm{Gd}$ as the primary components, solidifying the suggestion that the diffusion barriers were still attached to both sides of the specimens.

Attempts were made to remove the diffusion barrier from the metallic fuel sample but theses were not successful.

The samples were re-packaged and are in the process of shipping to INL collaborators. 


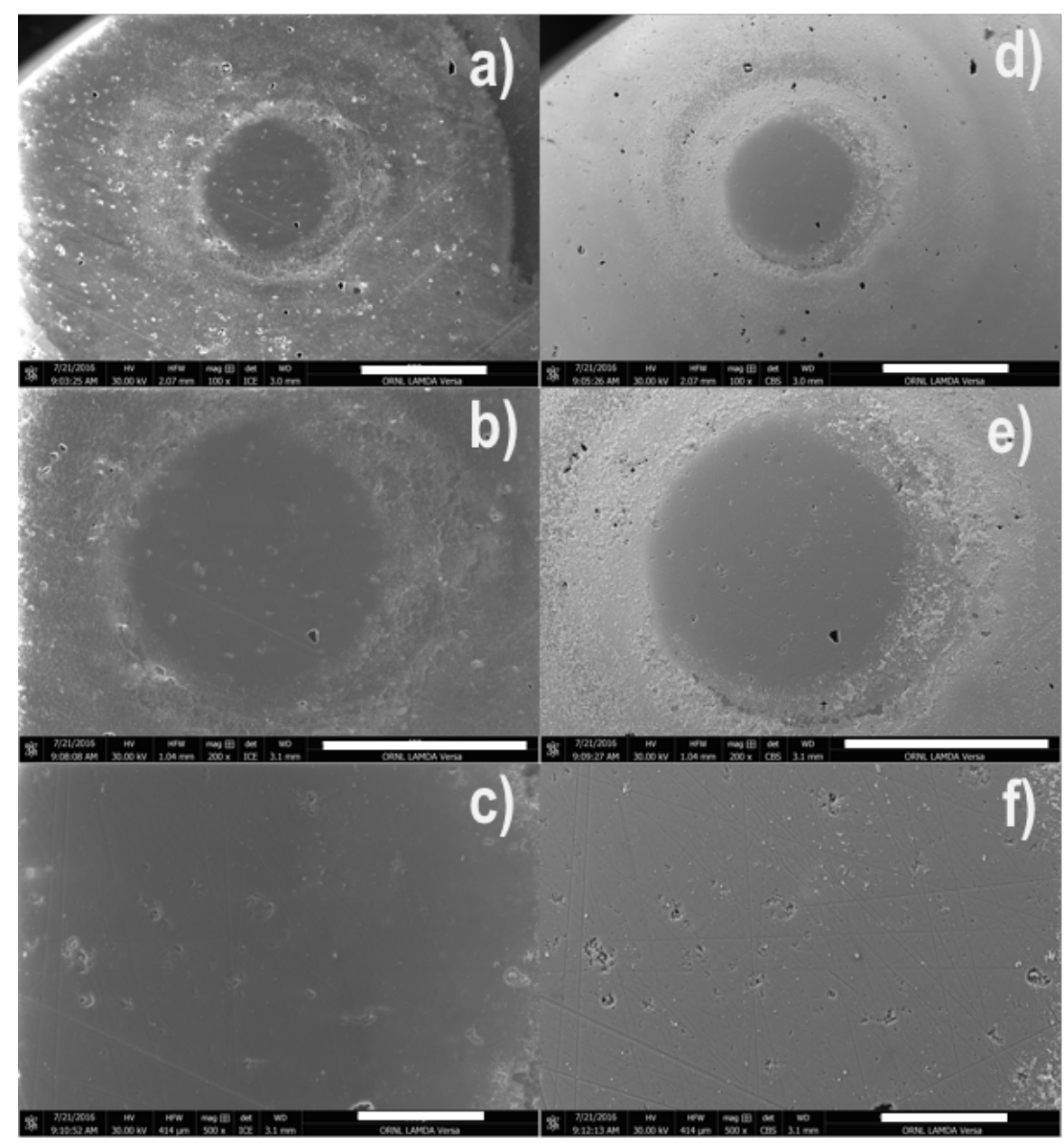

Fig. 2. SEM micrographs from the center of one side of the disk-shaped sample CP. a)-c) are secondary electron images; d)-f) are back-scatter electron images. The scale bars (white) are: a) \& d) $500 \mathrm{~nm}$, b) \& e) $400 \mathrm{~nm}$. c) \& f) $100 \mathrm{~nm}$. 


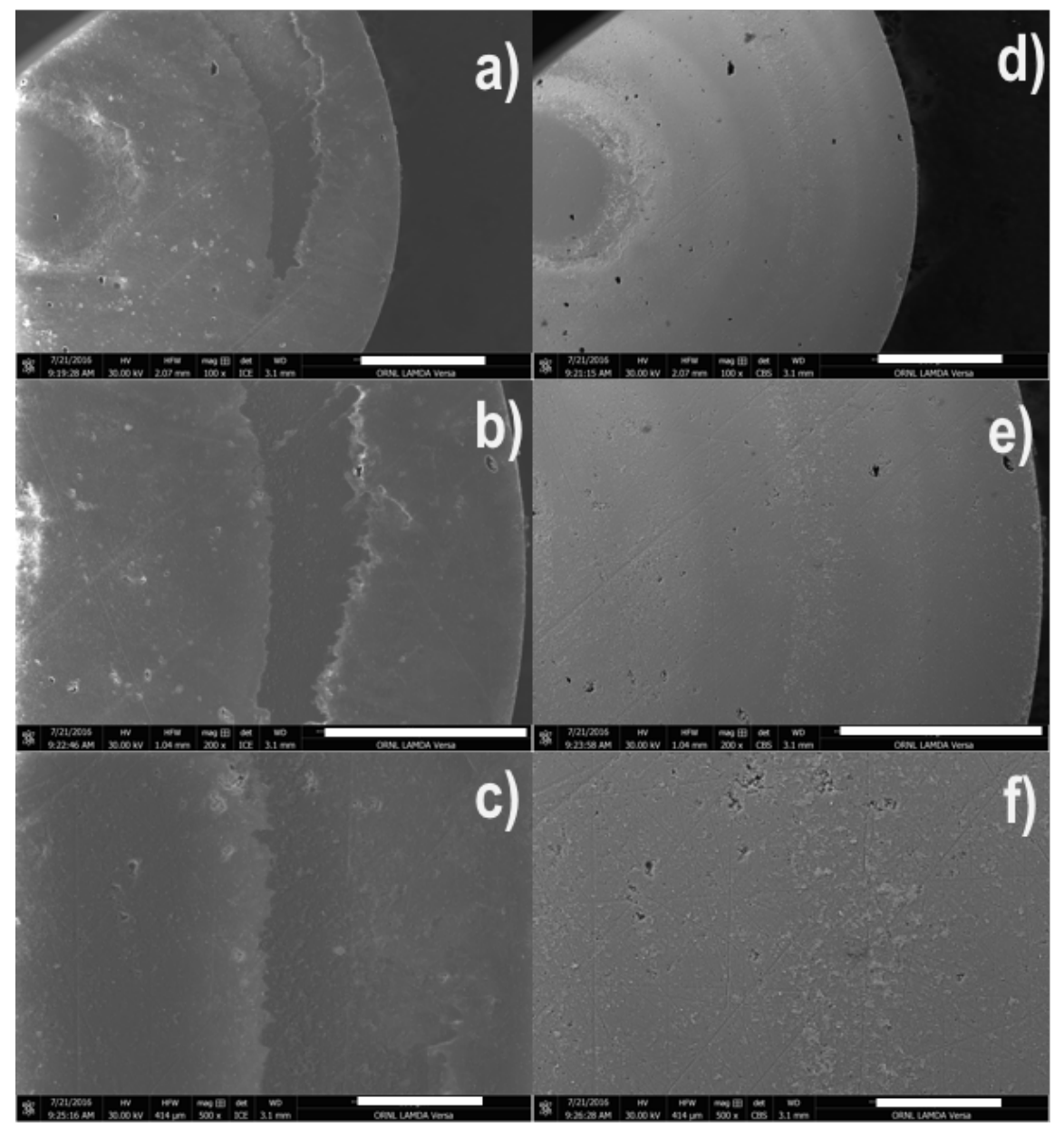

Fig. 3. SEM micrographs from the edge of of one side of the disk-shaped sample CP. a)-c) are secondary electron images; d)-f) are back-scatter electron images. The scale bars (white) are: a) \& d) $500 \mathrm{~nm}$, b) \& e) $400 \mathrm{~nm}$. c) \& f) $100 \mathrm{~nm}$. 


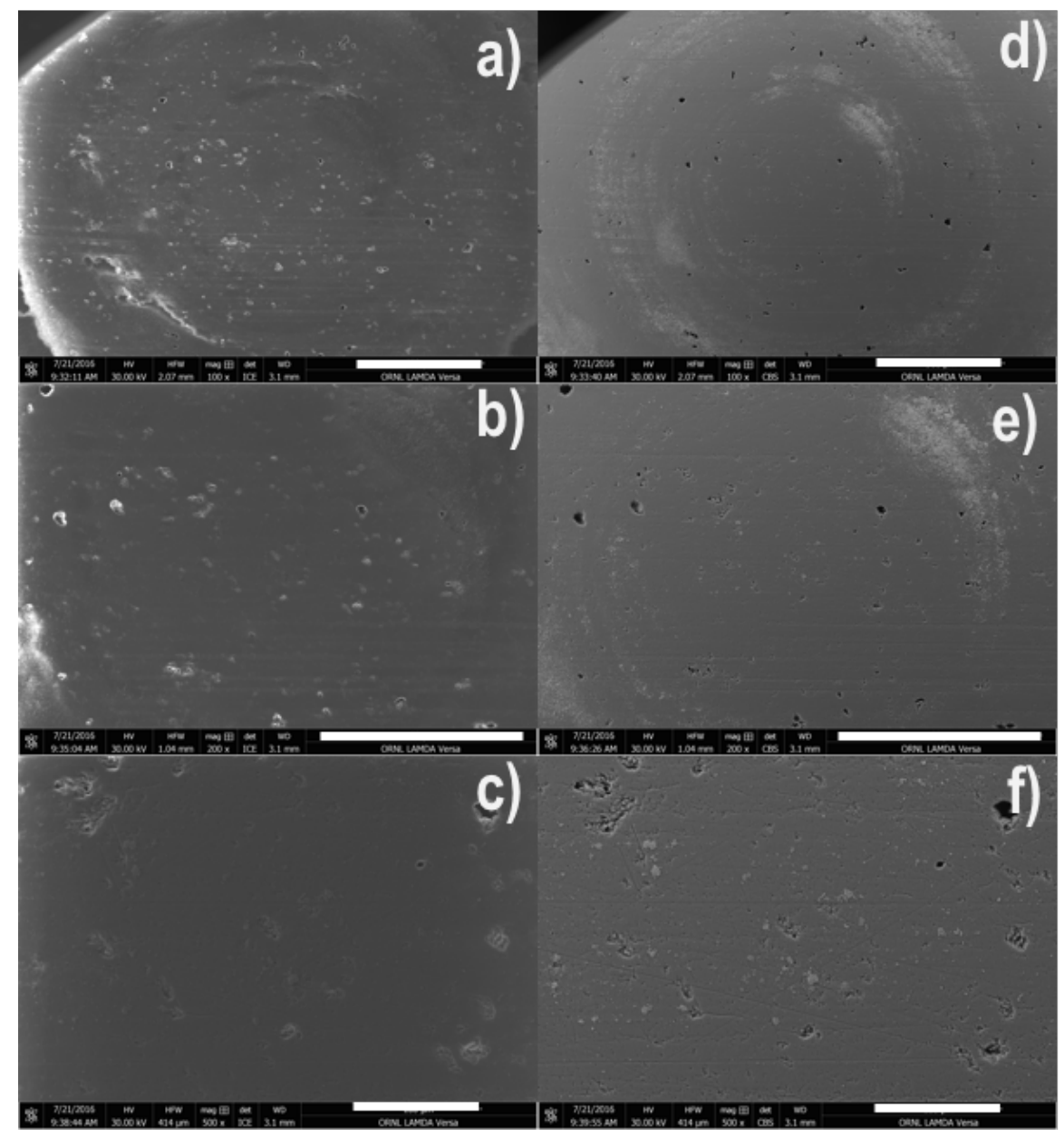

Fig. 4. SEM micrographs from the center of one side of the disk-shaped sample CZ. a)-c) are secondary electron images; d)-f) are back-scatter electron images. The scale bars (white) are: a) \& d) $500 \mathrm{~nm}$, b) \& e) $400 \mathrm{~nm}$. c) \& f) $100 \mathrm{~nm}$. 


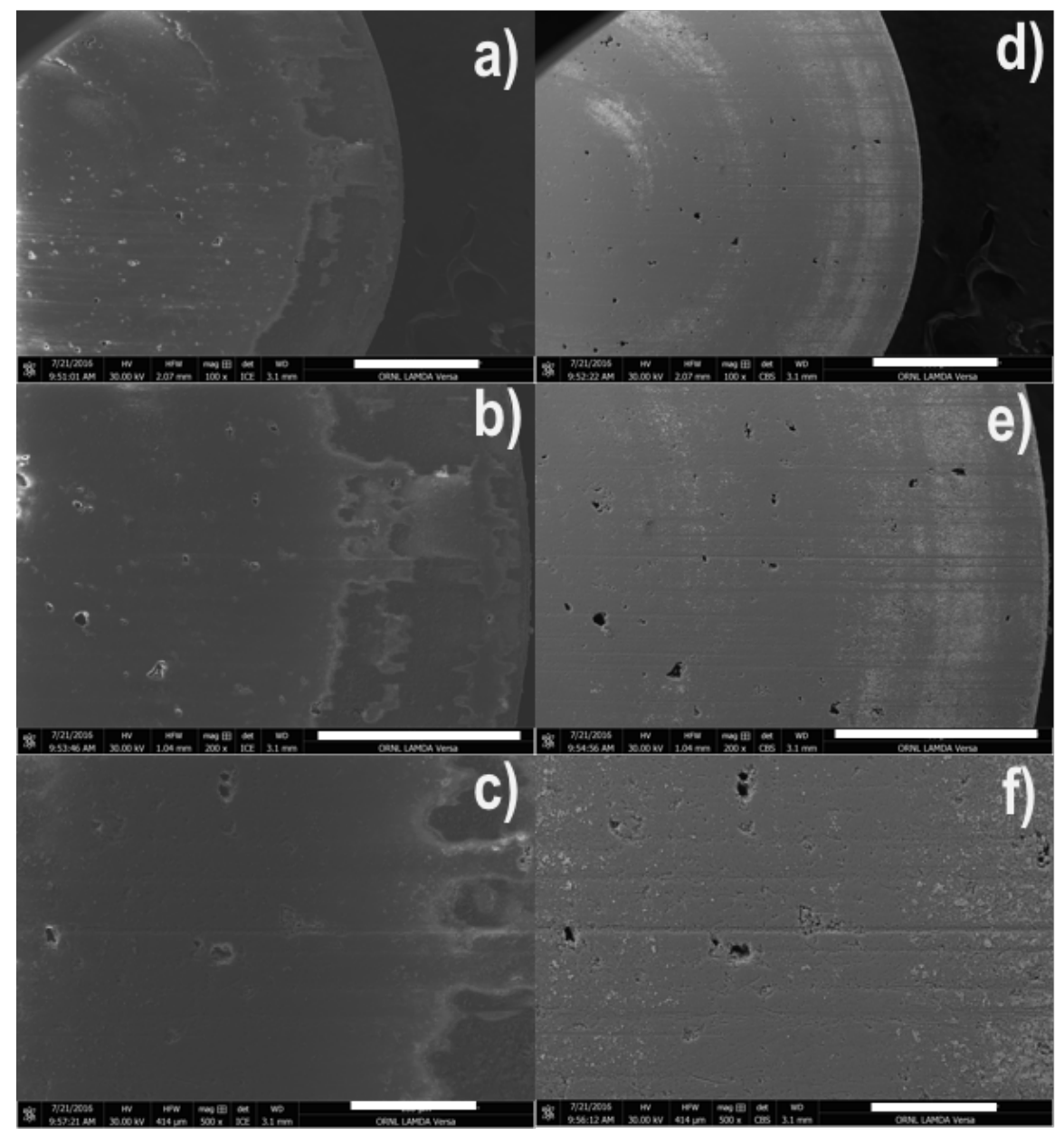

Fig. 5. SEM micrographs from the edge of of one side of the disk-shaped sample CP. a)-c) are secondary electron images; d)-f) are back-scatter electron images. The scale bars (white) are: a) \& d) $500 \mathrm{~nm}$, b) \& e) $400 \mathrm{~nm}$. c) \& f) $100 \mathrm{~nm}$. 


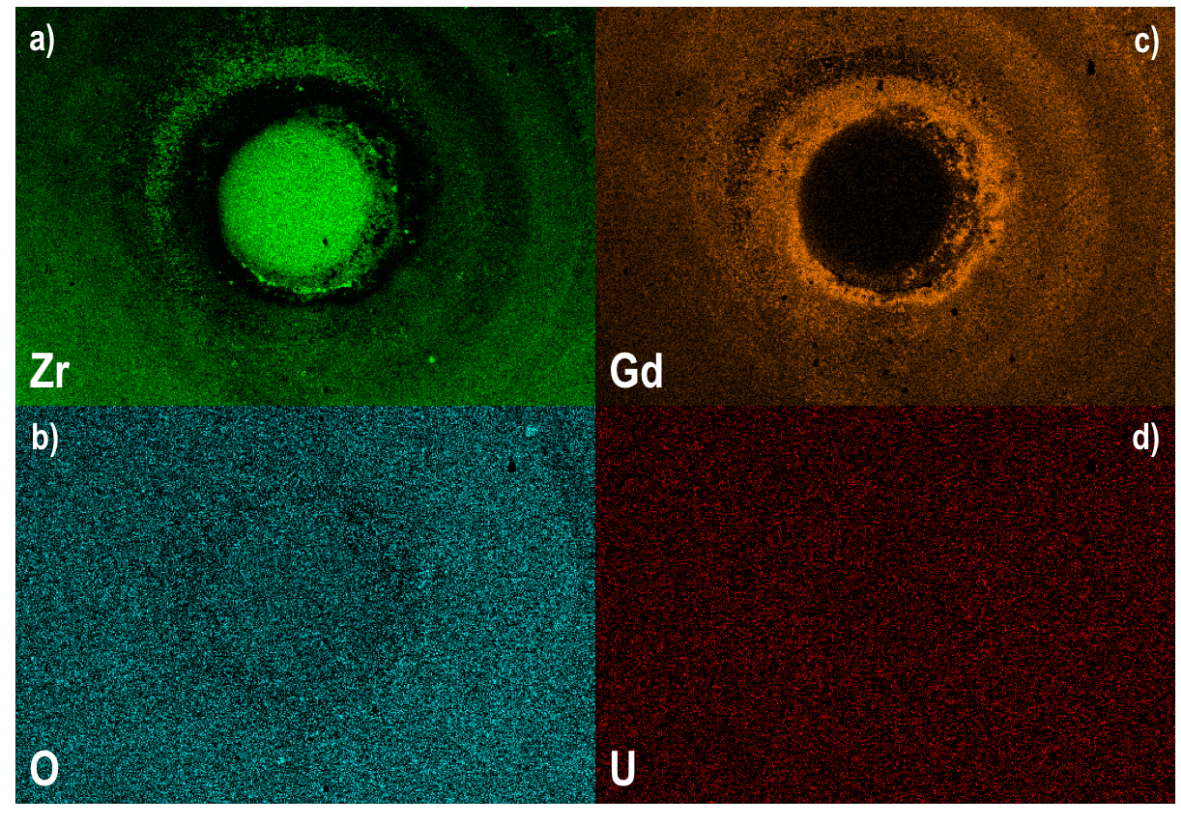

Fig. 6. EDS maps recorded from the center of the sample CP. Each map is $2 \mu \mathrm{m}$ across.

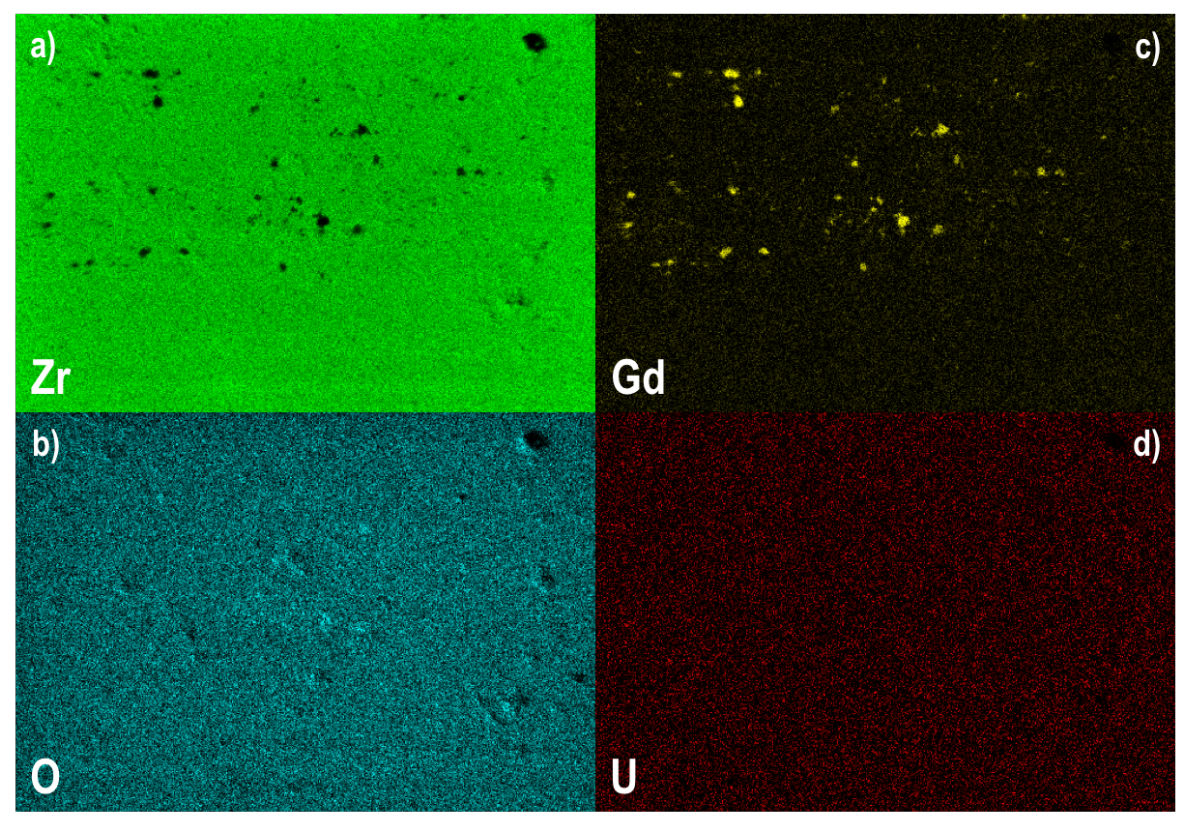

Fig. 7. EDS maps recorded from the edge of the sample CP. Each map is $2 \mu \mathrm{m}$ across. 


\subsubsection{Temperature Monitor Analysis}

Two parallelepiped and one disk-shaped temperature monitors were recovered from rabbit capsule FCT-141, Figure 8. Only the two parallelepiped temperature monitors (TMs) were characterized for maximum irradiation temperature. The disk-shaped TM was not characterized as no identification markings could be found, and as such it is not possible to know the precise location of the disk TM during irradiation.

The TM analysis was conducted using a Netzsch DIL 402 CD dilatometer located in ORNL's Low Activation Materials Development and Analysis (LAMDA) laboratory. The heating rate during analysis was $1 \mathrm{~K} / \mathrm{min}$. The results of the TM analysis for the two parallelepiped TMs (TM-280 and TM-294) is summarized in Figure 9. It was determined that the maximum irradiation temperature for this capsule was approximately $800{ }^{\circ} \mathrm{C}$.

The target irradiation temperature for the specimens was $700{ }^{\circ} \mathrm{C}$, with simulations predicting that the parallelepiped TMs reaching a temperature of $640{ }^{\circ} \mathrm{C}$. Therefore, these results indicate that the actual irradiation temperature was approximately $100{ }^{\circ} \mathrm{C}$ higher than anticipated.

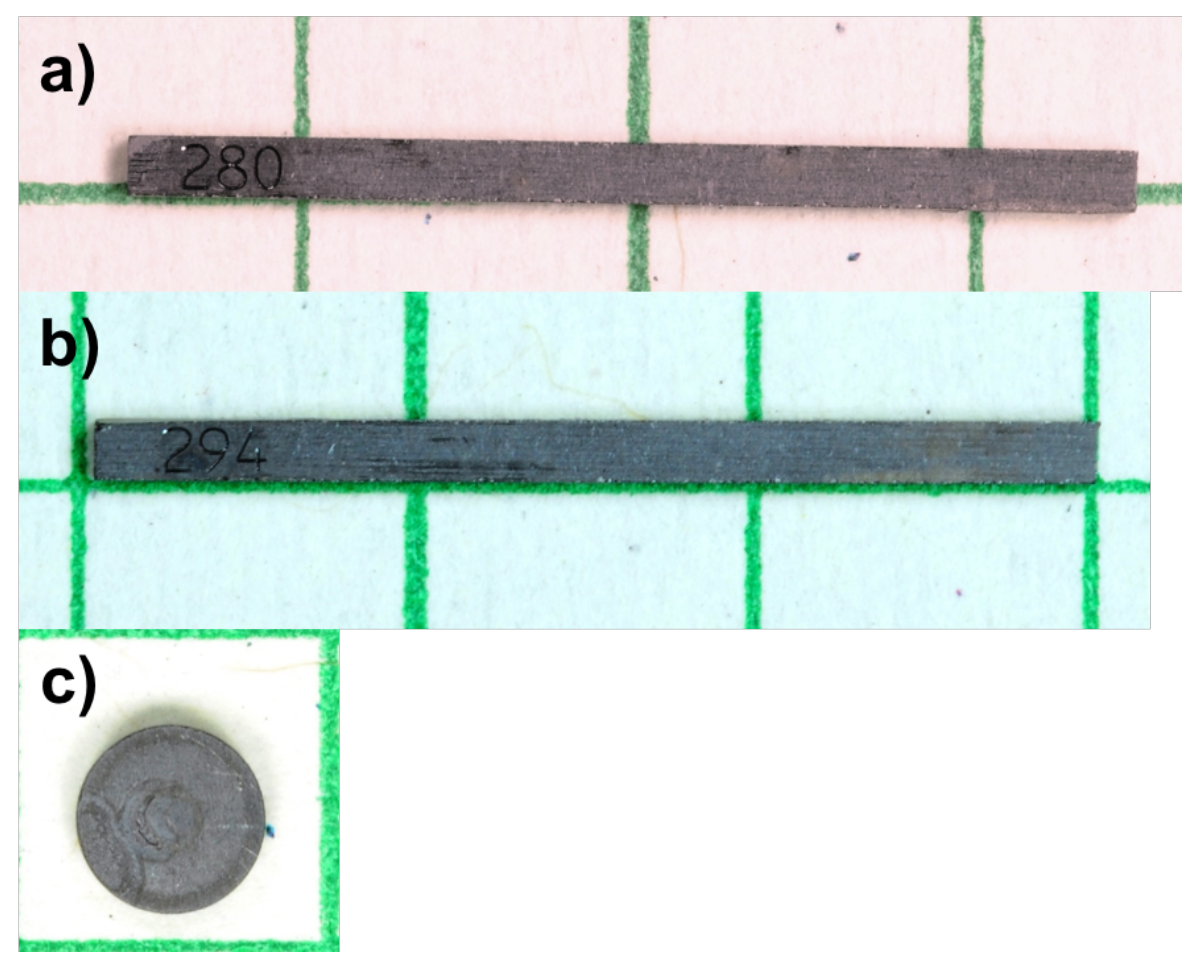

Fig. 8. Photographs of the SiC temperatures monitors recovered from FCT-141: a) TM-280, b) TM-294, c) disk TM (no identification). The scale between the green lines is $5 \mathbf{~ m m}$. 


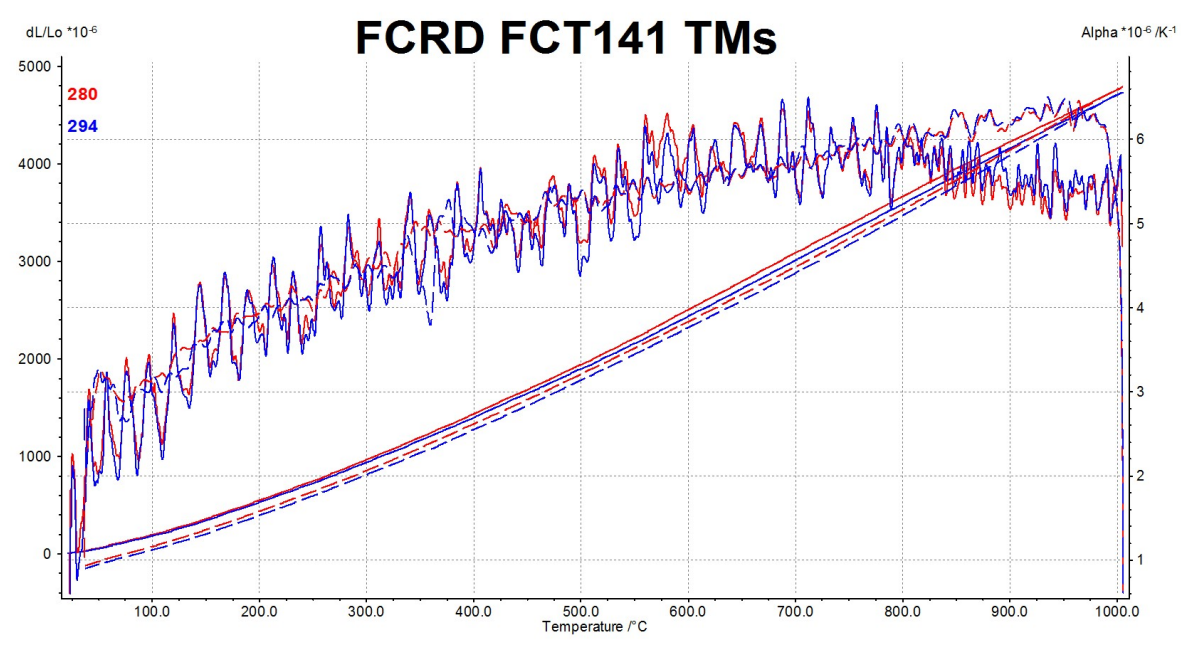

Fig. 9. Thermal analysis results from the temperature monitors recovered from the FCT-141 irradiation capsule. The results indicate a maximum irradiation temperature of $\sim 800{ }^{\circ} \mathrm{C}$. 



\section{FCRP IRRADIATION SERIES}

The FCRP series of irradiations are currently being performed and utilize the use of specimens of parallelepiped geometry. Additionally, lessons learned from the design of the FCT capsules (in which the Gd-shielding was internal to the secondary housing structure of the capsule) resulted in the moving of the Gd-shield from inside the internal housing, to outside. This redesign allows for more rapid transfer of the specimens to INL collaborators, and is shown schematically in Figure 10.

A summary of the status of the capsules is given in Table 2. Capsules FCRP-01-03 were shipped to INL in February 2016, and the SiC TMs are currently ready for transportation back to ORNL for analysis (as described in §2.1.2.2). DU specimens were received from INL in summer 2016 and have been loaded in readiness for HFIR irradiations, and will be irradiated in the near future.
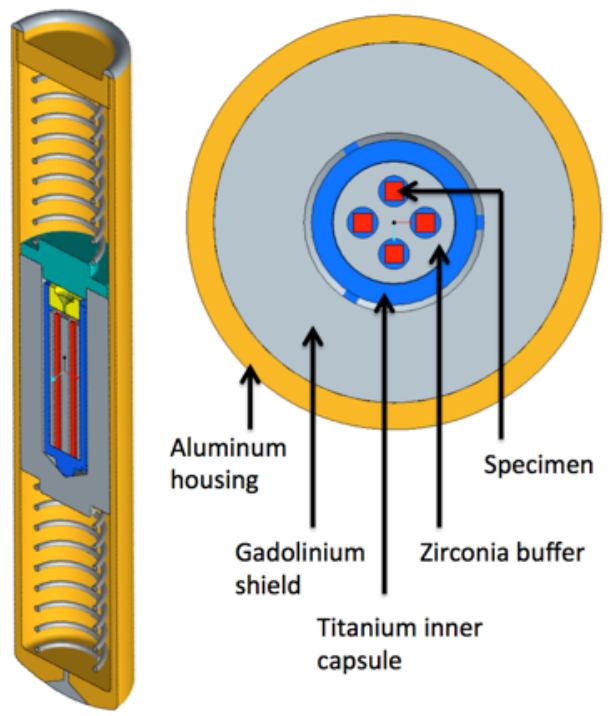

Fig. 10. FCRP parallelepiped-specimen rabbit capsule design using an outer Gd thermal neutron shield and a removable inner titanium specimen capsule.

Table 2. Summary of the irradiation conditions for the FCRP series of irradiations for parallelepipedshaped metallic fuel specimens.

\begin{tabular}{llcccc}
\hline Capsule & Specimen Material & Irradiation Time (hours) & Irradiation fluence $\left(\times 10^{22} \mathrm{n} \mathrm{m}^{-2}\right)$ & Irradiation Cycle & Status \\
\hline \hline FCRP-01 & Stainless Steel & 1.3 & 0.29 & 462 & At INL \\
FCRP-02 & Stainless Steel & 13 & 2.9 & 462 & At INL \\
FCRP-03 & Stainless Steel & 130 & 28 & 462 & At INL \\
FCRP-04 & DU & 13 (Target) & - & 468 & At ORNL, loaded in readiness for HFIR insertion \\
FCRP-05 & DU & 130 (Target) & - & 468 & At ORNL, loaded in readiness for HFIR insertion \\
\hline
\end{tabular}





\section{SUMMARY}

An overview of the current status of the HFIR irradiations in support of developing a deeper understanding of low fluence irradiations in metallic fuel systems for use in advanced nuclear systems has been presented. ORNL continues to support this activity and to date has developed new Gd-shield capsules that allow for the irradiation of TEM-style, general-purpose disk-shaped specimens, and parallelepiped specimens. To date, 5 capsules from the FCT irradiation series containing the disk-shaped specimens have been irradiated and are in the process of being shipped to INL collaborators. One capsule was opened at ORNL and some basic characterization in the form of SEM and EDS of the two fuel specimens, and analysis of the $\mathrm{SiC}$ temperature monitors has been performed.

The first irradiations of the FCRP series (parallelepiped specimen geometry) has been performed and the stainless steel specimens sent to INL. The SiC TM's are currently being sent back to ORNL for analysis. The first metallic fuel specimens have been received and are loaded into capsules awaiting insertion into HFIR. 